\title{
WATER IRRIGATION USING AROID (ARDUINO +ANDROID) EMBEDDED SYSTEM
}

\author{
Rumaesa Ansari, Kashif Khan, Aarati Naikal,Saurabh Patil \\ Final year Students Department of Computer Engineering, \\ Xavier Institute of Engineering, Mumbai University, Mumbai, India
}

\begin{abstract}
Watering is the best and most important practice of irrigation. It is also the most labor-intensive task in daily irrigation process. The two major aspects of watering are when to water and how much to water. To make the task of watering easy, the Arduino + Android application-based plant watering system is created. The present work uses an 8051 microcontroller. It is programmed to receive the input signal. The input signal is the varying moisture condition of the soil which can be sensed using an appropriate sensing arrangement. On receipt of the signal the controller generates an output which in turn a relay for operating the water pump. Also, for making it more farmer helping, it is having more features like crop monitoring (done by using CNN), fertilizer Recommendation, Lending business, weather detection (using API), etc.
\end{abstract}

Keywords- Microcontroller 8051, Irrigation, Soil Moisture Content, Manual Irrigation Mechanism, CNN, API, etc.

\section{INTRODUCTION}

Irrigation is the artificial application of water to the land or soil. During periods of inadequate rainfall Irrigation plays a major role . Apart from this irrigation also acts as key player in assisting the growth of agricultural crops, landscape maintenances, and re vegetation of disturbed soils in dry areas and during periods of inadequate rainfall.

Moisture sensors and the motor/water pump are two functional components used in this project.

we have used Moisture sensor to sense the level of moisture in the soil. Arduino Uno programmed with Arduino IDE used in this project controls the motor which supplies water to plants. Moisture in the soil is measured using moisture sensor and the signal is sent to Arduino if watering is required. Arduino Uno used in this project controls the motor which supplies water to plants. The moisture sensor measures the level of moisture in the soil and sends the signal to the Arduino if watering is required. The motor/water pump supplies water to the plants until the desired moisture level is reached.

The present projects provides a handy camera to allow the farmer to photograph an image of the crop when he wishes to diagnose. Also, the application helps to recommend the fertilizer to the field according to the area and land. This application is also helpful for the farmers to buy their needy product on rent from this application. also, this app will help to detect the weather of the area according to the location.

\section{II.EXISTING SYSTEM}

Most of the existing system developed are automatic which allows the water to be pumped to the plants automatically . Although it has many advantages it lacks in getting human control over the plants. The farmer/owner would have no idea about the status of the plants whether they are in good condition or not. In this way if the system fails the farmer would have no idea and there will be wastage of water.

The moisture level sensor used in our architect will give status about the plants/crops in the field and a notification will be sent to the owner through which he/she will decide whether to water the plants or not. We are using GSM in our project through which the farmer/owner can check the status about the plants and can water them from anywhere If the temperature increases 
or decreases than the expected temperature, it may affect the quality of the crops. This problem can be overcome by using the shielding mechanism, thereby maintaining the desired temperature. The project is relatively small in size because of which it can be used in fields as well as home.

\section{PROPOSED SYSTEM}

\section{Manual Control:}

It has human control system that means all the water pumping is done in the presence of the owner. After receiving the notification, the owner will know about the status of the moisture level present in the soil through which he will decide to water the plants or not.

\section{Crop Monitoring:}

The application provides a handy camera integration to allow the farmer to click an image of the crop he wishes to diagnose. This image is processed in the backend using a deep learning model to classify the plant disease.

\section{Fertilizer Recommendation:}

This application will help the framer to give fertilizer or pesticides to the crops or field according to the selection of area, type of plant and season and it also suggest the amount of pesticides or fertilizer in $\mathrm{kg}$ according to the user mentioned size of field in hector.

\section{Lending business:}

This application contains one part as little ecommerce part which will help the farmer to buy their needy products, tractors, other vehicles on rent for a particular time period, this feature will help the farmer to buy the costly items of their need with less cost for short period of time.

\section{Weather Detection:}

This application can detect weather according to the area selected with the help of weather API.

\section{WORKING}

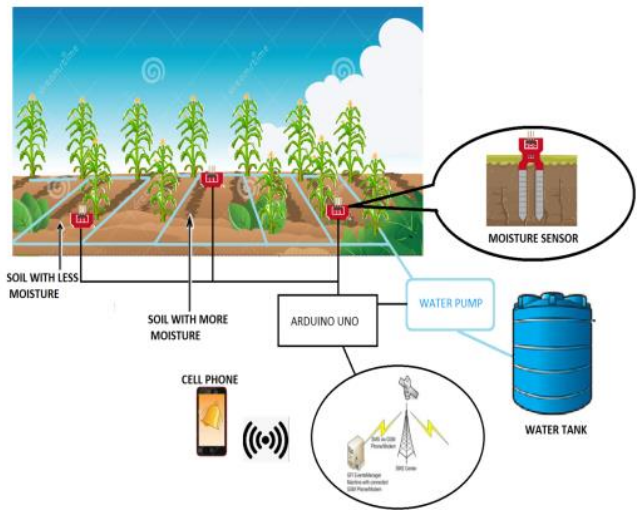

1. Irrigation System

The above diagram shows how the water is supplied to the field.

As you can see in the diagram the cell phone is connected to the Arduino UNO via GSM.

Sensor will sense the moisture level in the soil and if the moisture level is below the desired level,

A notification will be sent to the cell phone via network through which the owner can ON/OFF the water pump.

\section{Crop monitoring:}

In this module CNN (Convolution Neural Network) is best type of deep learning model, it is well known for its widely used in applications of image and video recognition and also in recommender systems and natural language processing. However, convolution is more efficient because it reduces the number of parameters which makes different from other deep learning models. 


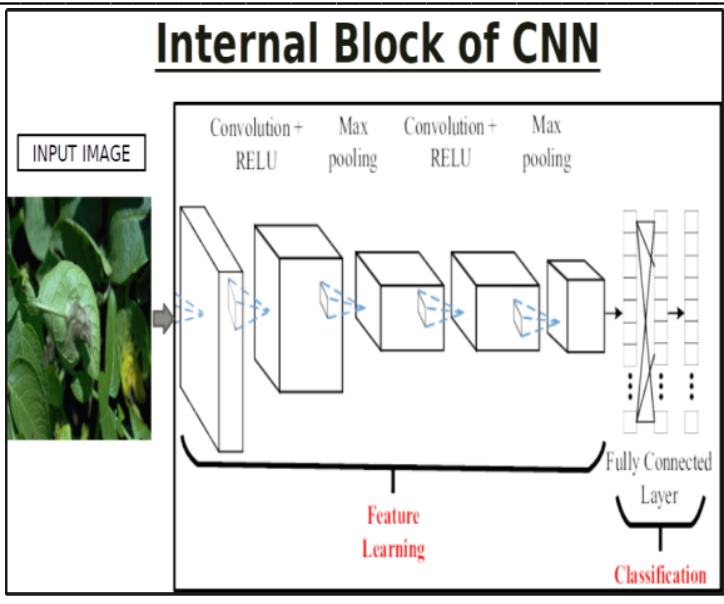

2. CNN internal blocks

1. Convolution: is the first layer to extract features from the input image and it learns the relationship between features using kernel or filters with input images.

2. ReLU Layer: ReLU stands for the Rectified Linear Unit for a non-linear operation. The output is $f(\mathrm{x})=$ $\max (0, \mathrm{x})$. we use this because to introduce the nonlinearity to CNN.

3. Pooling Layer: it is used to reduce the number of parameters by down sampling and retain only the valuable information to process further.

There are types of Pooling:

$$
\begin{aligned}
& \circ \quad \text { Max Pooling } \\
& \circ \quad \text { Average and sum pooling. }
\end{aligned}
$$

4. Flattening: we flatten our entire matrix into a vector like a vertical one. so, that it will be passed to the input layer.

5. Fully Connected Layer: we pass our flatten vector into input Layer. we combined these features to create a model. Finally, we have an activation function such as soft-max or sigmoid to classify the outputs.

\section{Fertilizer Recommendation:}

In this module, the process goes in the following manner:

1. Select the district.

2. Select the season (Kharif, Rabi and Zaid).

3. After selecting the season according to the area of district it will give option to select the crop.

4. Then it will give some information about the crop and then it will show the recommended pesticides.

5. Then user have to give the size of the field in hector and on pressing "calculate growth" it will show the recommended amount of pesticides needed in $\mathrm{kg}$.

\section{Weather detection:}

This module of our project gives the present weather of the specified city, with the help of online weather API (openweather platform). OpenWeather platform is a set of elegant and widely recognisable APIs. Powered by convolutional machine learning solution, it is capable of delivering all the weather information necessary for decisionmaking for any location on the globe.

\section{RESULTS}

1. Few snapshots of our application
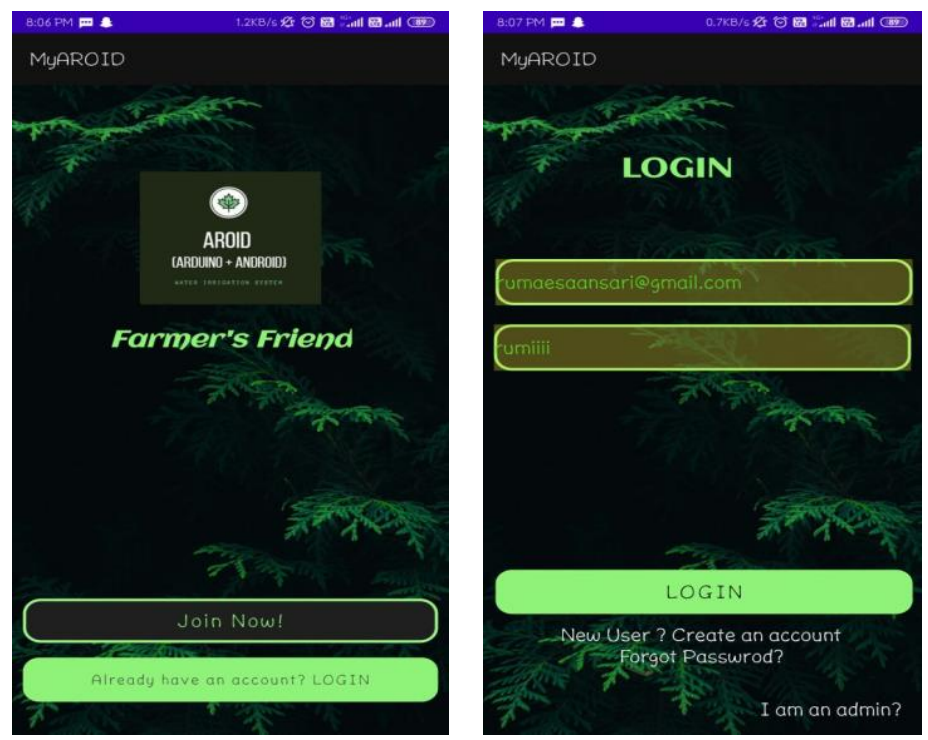

3. Login And other Pages 
2. Snapshots of Bluetooth connection, receiving moisture content from Arduino uno and command passing through cellphone.
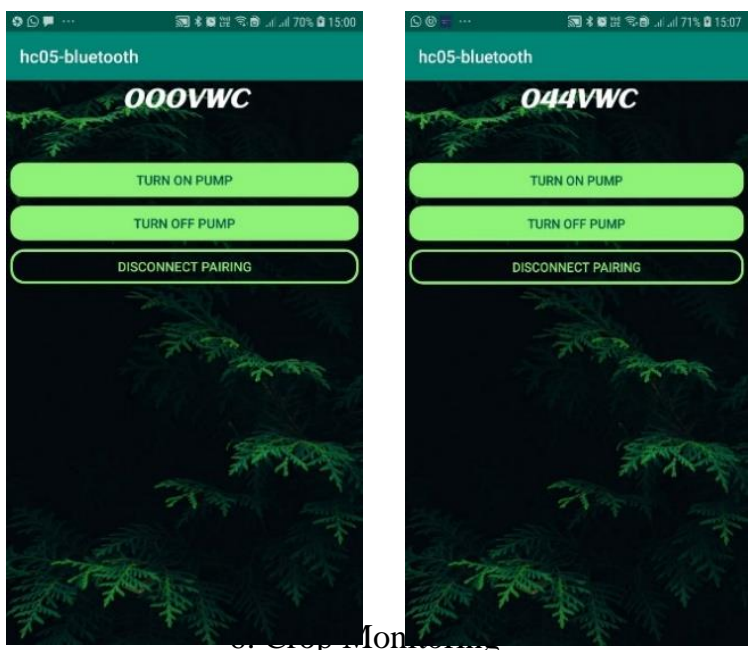

4. Bluetooth Module

3. In fertilizer recommendation for jowar field of 5 hector it recommends $2500 \mathrm{~kg}$ of the below pesticides.
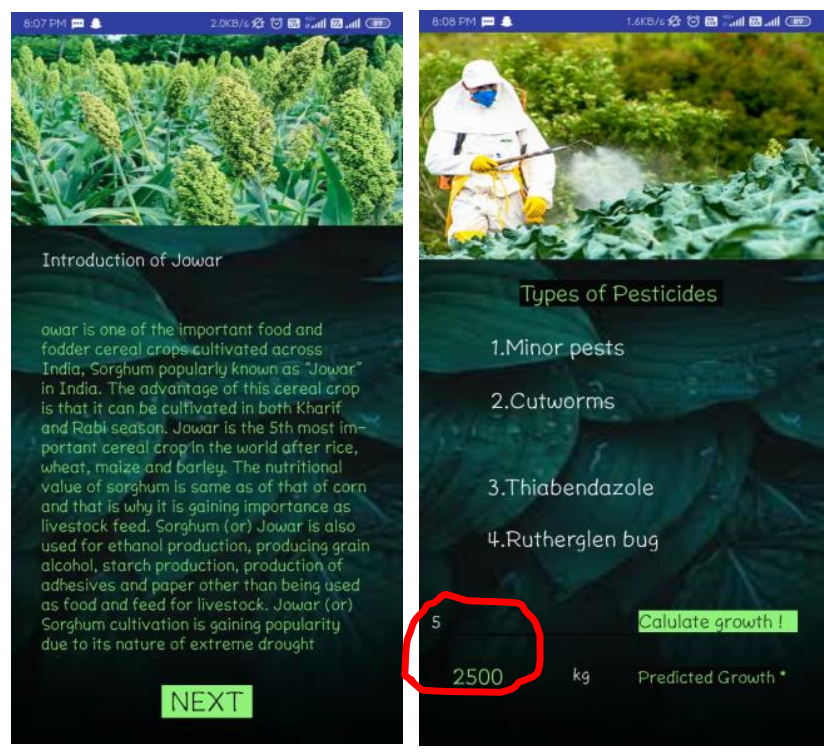

5. Fertilizer Recommendation

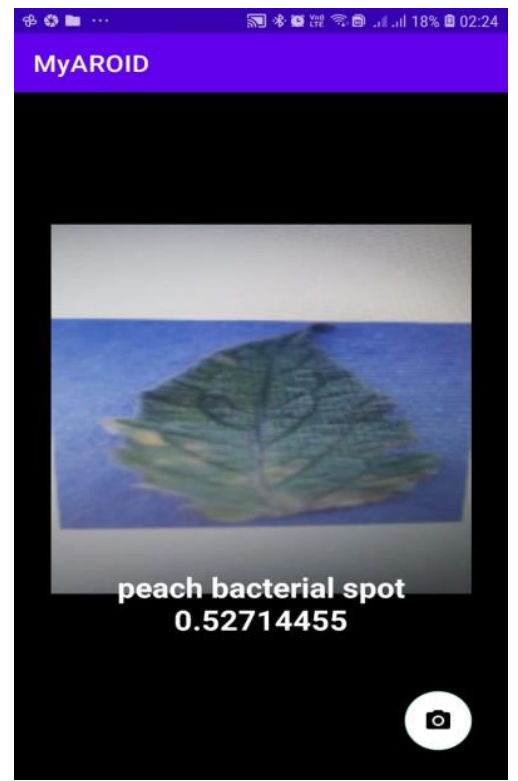

5. few screen shots of weather forecasting of different cities done on our app.
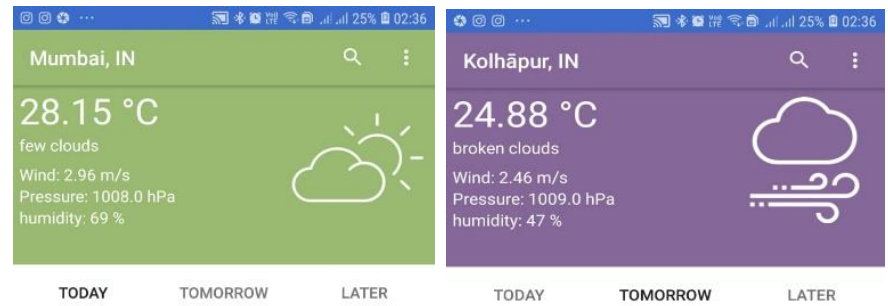

TODAY
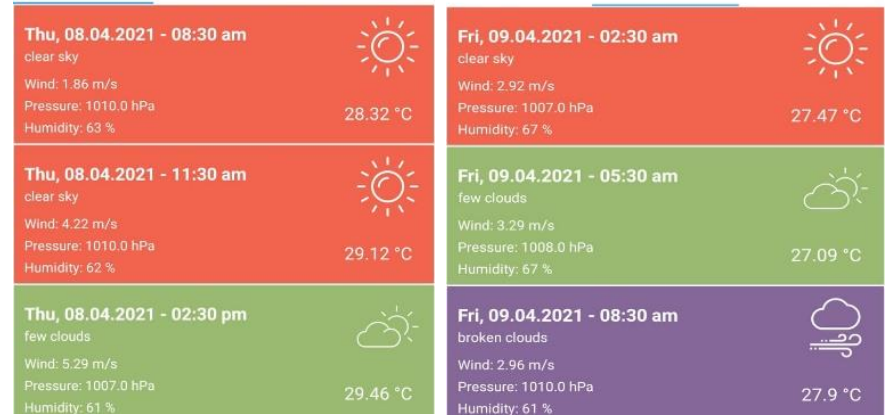

7. Weather Forecasting

4. After all the

crossing all the CNN stages, the app has shown that, there are peach bacterial spots on tomato leaf. 


\section{CONCLUSION}

In this paper, we have provided an overview of the actual state of the art regarding IoT irrigation systems for agriculture. We have identified the most monitored parameters to characterize water quality for irrigation, soil and weather conditions.

As future work, we are developing a smart irrigation system that evaluates water quality prior to irrigation based on the proposed architecture.

\section{REFERENCES}

[1] International Journal of Advancements in Research \& Technology, Volume 2, Issue4, April-2013 194.

[2] International Journal of Innovative Research in Computer and Communication Engineering (An ISO 3297: 2007 Certified Organization) Vol. 1, Issue 6, August 2013.

[3] Electrical and Electronics department Agricultural sciences, 2015.

[4] Department of Agricultural and biological engineering, UF/IFAS Extension, Review April 2014.

[5] Proceedings of the world congress on engineering and computer science 2015. Vol 1,WES 2015 , October 2123,2015,San Francisco, vfrt5hyum,imUSA.

\section{Websites:}

[1] http://www.scrip.org/journal.net

[3] http://edis.ifds.ufl.edu.net

[4] http://www.iaeng.org/publication/WCECS2015.html

[5] https://www.edgefx.in/automatic-plant-irrigation-system-

circuit-and-its- working.net

[6] https://www.elprocus.com/microcontroller-based-

automatic-irrigation-system/

[7] https://www.linkedin.com/.../agriculture-projects-

irrigation-based-8051-avr-msp430 